Research Article

\title{
Comparison of efficacy of high dose inhaled corticosteroids with a combination of low dose inhaled corticosteroids and long acting $\beta 2$ agonists in patients of moderate persistent asthma : a randomised prospective comparative study
}

\author{
Vivek Sood*, Parveen Sharma, Rekha Bansal, Dinesh Kansal
}

Department of Pharmacology, Dr. RPGMC, Kangra, Himachal Pradesh, India

\section{Received: 16 March 2016 \\ Revised: 10 May 2016 \\ Accepted: 12 May 2016 \\ *Correspondence to: \\ Dr. Vivek Sood, \\ Email: drviveksood \\ @yahoo.co.in}

Copyright: (C) the author(s), publisher and licensee Medip Academy. This is an openaccess article distributed under the terms of the Creative Commons Attribution NonCommercial License, which permits unrestricted noncommercial use, distribution, and reproduction in any medium, provided the original work is properly cited.

\begin{abstract}
Background: Asthma has global prevalence varying from 2-25\%. Among various subtypes, moderate persistent asthma is a subtype currently managed by a combination therapy of low dose inhaled corticosteroids and LABA (long acting $\beta 2$ agonists). Search is on for LABA free regime because of safety concerns and increased risk of exacerbations as reported in meta-analysis conducted by FDA in 2008.

Methods: Patients (new and old) of either sex and age having moderate persistent asthma as per GINA 2004 guidelines were enrolled and allocated in two groups using block randomization. DPIs (dry powder inhalation) were used in the study. Budecort group subjects were treated with budesonide $400 \mu \mathrm{g}$ rotacaps twice a day. Foracort group subjects were treated with combination rotacaps of formoterol $6 \mu \mathrm{g}$ with budesonide $200 \mu \mathrm{g}$ twice a day. Follow up period in study was nine months with quarterly spirometry assessment.

Results: In 63 enrolled cases, there was no significant difference in intergroup spirometry comparison at baseline and at 9 months. The difference at 9 months in spirometry as compared from baseline in each group was also not statistically significant. Numerically, budecort group showed slightly better values.

Conclusions: The therapy in each group was comparable in terms of efficacy. This is important due to the fact that therapy in current use for moderate persistent asthma is combination therapy. So use of high dose inhaled steroid therapy used as $400 \mu \mathrm{g}$ rotacaps with matching revolizer twice a day $(800 \mu \mathrm{g}$ daily) may be good alternative to use of combination therapy particularly in patients where LABA cannot be used.
\end{abstract}

Keywords: Asthma treatment, Moderate persistent asthma treatment, High dose steroids in asthma, Combination therapy in asthma, Long acting $\beta 2$ agonists, Dry powder inhalation use

\section{INTRODUCTION}

In terms of extent and disability duration, asthma is $14^{\text {th }}$ most important disorder in the world affecting more than 300 million people globally. Globally, the prevalence of asthma varies from $2-25 \%{ }^{1}$ In India, certain metros like Delhi have more than $6 \%$, Chandigarh has $2.5 \%$ to $6 \%$ and Pune has less than $2.5 \%$ prevalence. ${ }^{2}$ Apart from environmental variations, the fact that most patients of mild asthma do not report to health facilities and remain undetected contributes to wide variation in prevalence.

\section{Aetiology and triggers}

Genetics, allergies, respiratory infections, irritants and air pollution play an important role in the development of asthma. ${ }^{3}$ Other risk factors are airway hyper responsiveness, lower maternal age, prematurity, low birth weight, duration of breast feeding and atopy. Combination of these factors causes asthma which involves airway inflammation, intermittent airflow obstruction and bronchial hyper responsiveness occurring due to release of various interleukins and leukocytes in response to antigenic stimulation. During an asthma 
attack, the mucosal lining of the bronchial passages swell, causing the airways to narrow and reduce the flow of air into and out of the lungs. ${ }^{4}$ Asthma symptoms can differ for each person. Wheezing, frequent coughs, shortness of breath and chest tightness are common symptoms. The latter is usually first to occur in a flare up. In addition, several stimuli can act as triggers. These include upper respiratory tract viral infections, cold air, allergens and stress.

\section{Management}

Appropriate management can control the disease and enable people to enjoy a good quality of life. This can be done by using reliever therapies and/or controller therapies in accordance with prevailing global initiative for asthma (GINA) guidelines. Among controllers, inhaled corticosteroids are the most effective antiinflammatory agents available for the treatment of asthma as they reduce morbidity and mortality. The long-acting $\beta 2$-agonists drugs are the most widely used sympathomimetic among relievers for treatment of the bronchoconstriction of asthma. As per GINA 2004 guidelines, moderate persistent asthma is usually managed by single line of therapy which is use of combination therapy comprising low dose inhaled corticosteroids and $\beta 2$ agonists. Current study wanted to explore additional treatment options for such patients if they needed therapy change due to adverse effects or due to inadequate response. It is with this novel intention of offering an additional treatment option of giving high doses $(800 \mu \mathrm{g})$ of inhaled corticosteroids to nonresponsive moderate persistent asthma patients, the current study was planned.

\section{Adverse effects}

Both the LABA and high dose steroid therapy use can have adverse effects. Systemic side effects of inhaled corticosteroids therapy are decrease in bone mineral density, hypothalamic-pituitary-adrenal axis suppression, impaired growth in children, and reduction in growth velocity, glaucoma, skin thinning, bruising and cataracts. 5 On the other hand, commonest adverse effects of LABA use are tremors, tachycardia and cardiac dysrhythmia. ${ }^{7}$ LABA prescribed as mono therapy may also increase the risk of asthma death in certain circumstances, such as the unsupervised off-label use without concomitant inhaled corticosteroids in patients with unstable asthma. ${ }^{8}$ Food and drug administration advisory has been issued for all medications containing a LABA stating that they have been associated with an increased risk of severe asthma exacerbations and asthma-related death. ${ }^{9}$ Concerns about the safety of longacting $\beta 2$-agonist therapy has led to the appearance of multiple publications and recommendations. On the basis of nearly 20 systematic reviews and databases, it has been found that LABA monotherapy significantly increases the risk of asthma-related adverse effects. ${ }^{10}$ Search is on for LABA free regime because of safety concerns and increased risk of exacerbations as reported in metaanalysis conducted by FDA in 2008.

\section{GINA guidelines}

Global Initiative for Asthma is a global body which periodically issues guidelines on asthma. The current study followed GINA 2004 guidelines which are convenient to physicians and prospectively grade the disease as mild, moderate and severe. GINA 2015 guidelines have been issued in which the diagnosis of asthma on the basis of severity has been replaced with diagnosis on the basis of control. So now the diagnosis on the basis of severity has to be done retrospectively. However, the treatment remains almost same and moderate persistent asthma corresponds to step 3 of GINA 2015 guidelines.

\section{METHODS}

This randomized prospective comparative study was conducted in the department of pharmacology and pulmonary medicine, Dr. RPGMC Kangra at Tanda after getting approvals of protocol review and institutional ethics committees.

Consecutive patients (new and old) of either sex and of any age diagnosed by physician as having moderate persistent asthma as per global initiative for asthma (GINA) 2004 updated guidelines were included in the study. (Table 1) Patients not willing to participate were the exclusion criteria.

\section{Table 1: GINA 2004 updated guidelines of moderate persistent asthma.}

Symptom during daytime -daily and attacks affect
activity
Symptom during night $>1$ time a week
PEF or FEV1 $60 \%-80 \%$
PEF variability $>30 \%$
Note: The presence of one of the features of severity is
sufficient to place a patient in this category.

154 patients having asthma or suspected of having asthma were screened in this study. Screening was done based on history, complaints and appropriate investigational methods including spirometry (Figure 1). 63 consecutive patients having moderate persistent asthma diagnosed as per GINA 2004 updated guidelines were enrolled for the study after written informed consent. 10 patients dropped out for various reasons. Enrolled patients were allocated in two groups using block randomization on the basis of age, gender and comorbidities to keep the groups comparable. All patients underwent baseline spirometry assessment. Dry powder inhalations (DPI) in rotacap formulation were used in the study with matching revolizer. Budecort group subjects were treated with budesonide $400 \mu \mathrm{g}$ rotacap twice a day. 
Foracort group subjects were treated with combination of formoterol $6 \mu \mathrm{g}$ and budesonide $200 \mu \mathrm{g}$ rotacap twice a day. All subjects were intensively counselled about method of use of rotacaps at each contact. In addition, separate counselling sessions were held by specialist physicians and subject experts twice a year for all study subjects to educate them about use of correct inhalation method and maintenance hygiene of the machine. Subjects were also instructed at every visit to rinse their mouth and gargle after every inhalation. All patients were followed up for a period of nine months from the date of enrolment at quarterly intervals for improvement. Spirometry was repeated at quarterly interval. Patients were advised to use reliever therapy in form of levosalbutamol rotacaps on SOS basis.

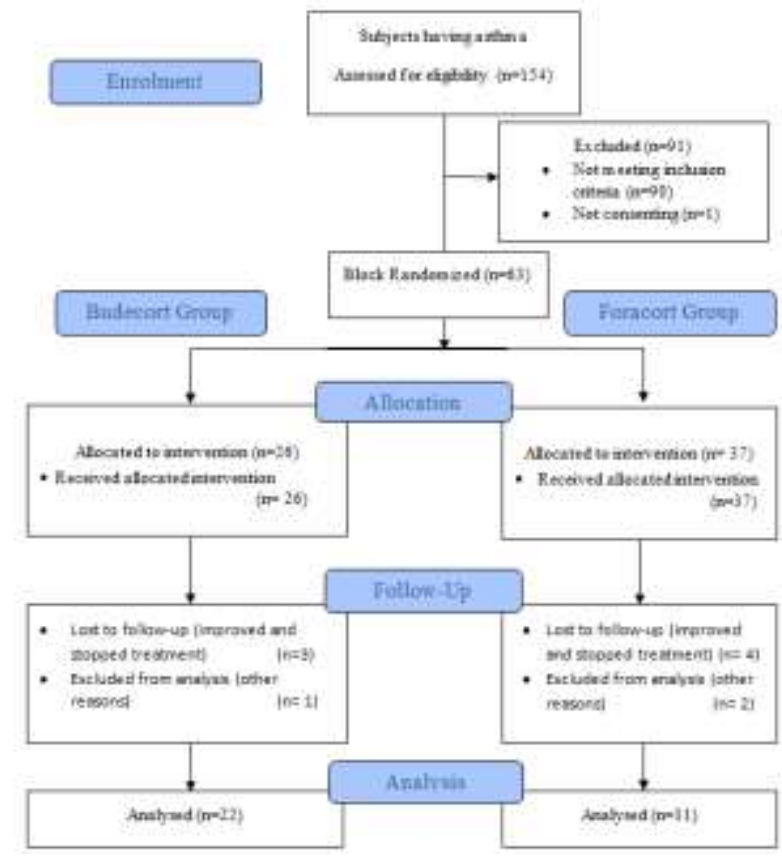

Figure 1: CONSORT flow diagram.

\section{RESULTS}

In budecort group, the mean $\pm \mathrm{SD}$ ( $\mathrm{p}$ values) of age, height, weight and BMI were respectively $37 \pm 16$ years, $153.4 \pm 9.4 \mathrm{~cm}, 52.7 \pm 11.2 \mathrm{~kg}$ and $22.2 \pm 3.3$. On the other hand for foracort group, the corresponding values were $43 \pm 16$ years, $155.2 \pm 9.2 \mathrm{~cm}, 54.4 \pm 13.7 \mathrm{~kg}$ and $22.4 \pm 4.5$. The difference between these groups was not significant (p-values $0.2,0.47,0.63$ and 0.87 respectively). So the two groups were found age and BMI matched. 10 males and 21 females remained in foracort group. Similarly, 7 males and 15 females remained in budecort group. The two groups were comparable regarding gender distribution ( $\mathrm{p}$ value 0.97 ).

\section{Spirometry means distribution in two groups}

Spirometry was done at quarterly intervals as per protocol.
- Intergroup assessment of improvement

Table 2: Spirometry means distribution comparison in two groups.

\begin{tabular}{|c|c|c|c|}
\hline & GP & $\begin{array}{l}\text { Mean } \pm \text { Std } \\
\text { Deviation }\end{array}$ & $\begin{array}{l}P \\
\text { value }\end{array}$ \\
\hline \multirow{2}{*}{ FVC } & Budecort & $80.86 \pm 15.21$ & \multirow{2}{*}{.857} \\
\hline & Foracort & $81.68 \pm 16.64$ & \\
\hline \multirow{2}{*}{ FEV1 } & Budecort & $68.59 \pm 21.85$ & \multirow{2}{*}{.936} \\
\hline & Foracort & $68.10 \pm 22.26$ & \\
\hline \multirow{2}{*}{ FEV1/FVC } & Budecort & $85.95 \pm 21.88$ & \multirow{2}{*}{.849} \\
\hline & Foracort & $84.90 \pm 18.03$ & \\
\hline \multirow{2}{*}{ PEFR } & Budecort & $55.64 \pm 27.17$ & \multirow{2}{*}{.465} \\
\hline & Foracort & $50.55 \pm 22.93$ & \\
\hline \multirow{2}{*}{ FEF2575 } & Budecort & $48.41 \pm 29.77$ & \multirow{2}{*}{.456} \\
\hline & Foracort & $42.74 \pm 24.99$ & \\
\hline \multirow[t]{2}{*}{ FVC $3 \mathrm{~m}$} & Budecort & $90.47 \pm 16.97$ & .248 \\
\hline & Foracort & $84.81 \pm 15.30$ & \\
\hline \multirow{2}{*}{ FEV1 $3 \mathrm{~m}$} & Budecort & $78.37 \pm 21.90$ & \multirow{2}{*}{.697} \\
\hline & Foracort & $76.04 \pm 17.99$ & \\
\hline \multirow{2}{*}{ FEV1/FVC 3 m } & Budecort & $90.16 \pm 18.09$ & \multirow{2}{*}{.776} \\
\hline & Foracort & $91.81 \pm 19.73$ & \\
\hline \multirow{2}{*}{ PEFR $3 \mathrm{~m}$} & Budecort & $62.32 \pm 28.24$ & \multirow{2}{*}{.855} \\
\hline & Foracort & $60.96 \pm 21.17$ & \\
\hline \multirow{2}{*}{ FEF2575 $3 \mathrm{~m}$} & Budecort & $53.05 \pm 23.48$ & \multirow{2}{*}{.705} \\
\hline & Foracort & $50.35 \pm 23.54$ & \\
\hline \multirow{2}{*}{ FVC 6 m } & Budecort & $91.17 \pm 14.63$ & \multirow{2}{*}{.191} \\
\hline & Foracort & $83.83 \pm 18.17$ & \\
\hline \multirow{2}{*}{ FEV1 $6 \mathrm{~m}$} & Budecort & $79.44 \pm 20.85$ & \multirow{2}{*}{.486} \\
\hline & Foracort & $74.78 \pm 18.83$ & \\
\hline \multirow{2}{*}{ FEV1/FVC 6 m } & Budecort & $89.44 \pm 20.53$ & \multirow{2}{*}{.568} \\
\hline & Foracort & $92.89 \pm 14.84$ & \\
\hline \multirow{2}{*}{ PEFR $6 \mathrm{~m}$} & Budecort & $69.72 \pm 32.41$ & \multirow{2}{*}{.512} \\
\hline & Foracort & $63.28 \pm 25.58$ & \\
\hline FEF2575 $6 \mathrm{~m}$ & Budecort & $56.61 \pm 28.44$ & .557 \\
\hline & Foracort & $51.50 \pm 22.99$ & \\
\hline FVC $0 \mathrm{~m}$ & Budecort & $87.79 \pm 9.58$ & 120 \\
\hline rvesm & Foracort & $74.00 \pm 17.97$ & .120 \\
\hline FEV1 $9 \mathrm{~m}$ & Budecort & $81.43 \pm 19.85$ & 117 \\
\hline FEV $19 \mathrm{~m}$ & Foracort & $67.25 \pm 24.67$ & .117 \\
\hline 1/FVC $9 \mathrm{~m}$ & Budecort & $86.36 \pm 21.74$ & \\
\hline FEVI/FVC $9 \mathrm{~m}$ & Foracort & $92.50 \pm 17.90$ & $14<$ \\
\hline PFFR $0 \mathrm{~m}$ & Budecort & $65.36 \pm 29.62$ & 105 \\
\hline PEFK Y $\mathrm{m}$ & Foracort & $51.33 \pm 22.83$ & .195 \\
\hline 257 & Budecort & $55.50 \pm 26.85$ & 523 \\
\hline ГЕГसЈIS & Foracort & $48.50 \pm 28.19$ &.$J 2$ \\
\hline
\end{tabular}

There was no significant difference in intergroup spirometry comparison at baseline and at end of 9 months. Intergroup comparison of FVC, FEV1, FEV1/FVC, PEFR, FEF2575 at baseline had p values of $0.85,0.94$, $0.85,0.47,0.45$ and at 9 months had values $0.12,0.12$, $0.45,0.20,0.52$ respectively (Table 2 ). The mean results comparison for spirometry parameters for both the groups at baseline and at the end of follow up did not show significant difference. 
- Intragroup assessment of improvement with time

Assessment of improvement in condition of subjects was done by measuring spirometry parameters and comparing increments or decrements with baseline values. Although statistical comparison (Table 3, 4) did not show significant improvement, mild improvement can be seen in time progression graphs (Figure 2-4).

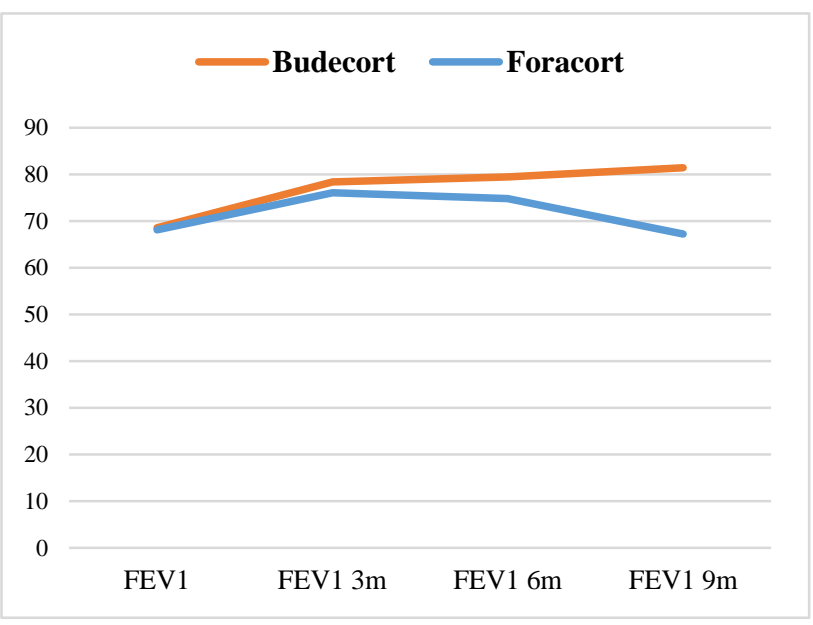

Figure 2: FEV1 time progression in two study groups.

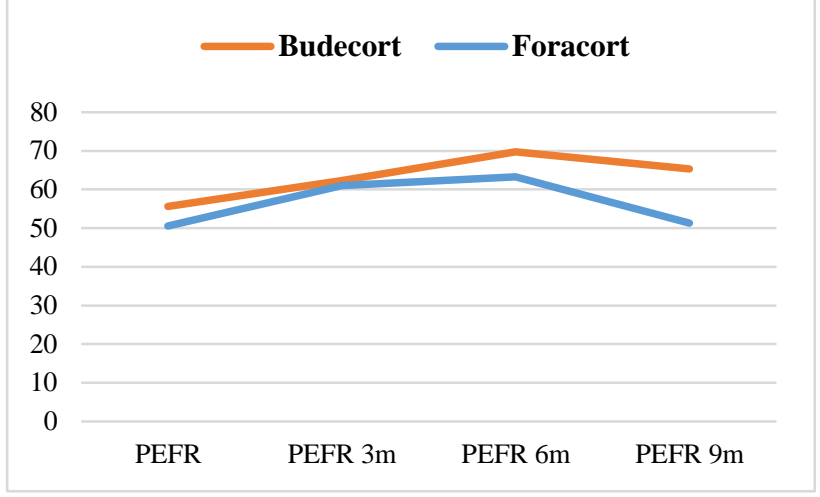

Figure 3: PEFR time progression in two study groups.

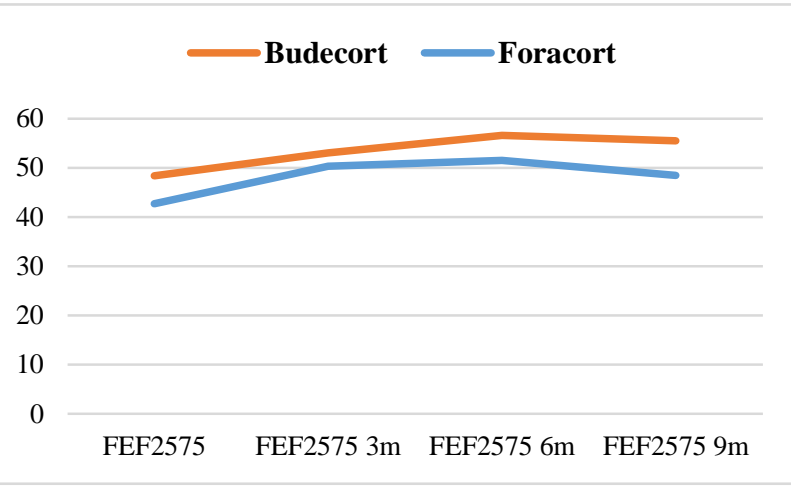

Figure 4: FEF 2575 time progression in two study groups.

Table 3: Spirometry means values progression with time (Budecort group).

\begin{tabular}{|c|c|c|c|c|c|c|}
\hline \multirow{2}{*}{ Group } & & & \multirow{2}{*}{ Mean \pm SD } & \multicolumn{2}{|c|}{$\mathbf{9 5 \%}$ Confidence interval for mean } & \multirow{2}{*}{ Sign. } \\
\hline & & & & Lower bound & Upper bound & \\
\hline \multirow{20}{*}{ Budecort } & \multirow{4}{*}{ FVC } & BASELINE & $80.86 \pm 15.2$ & 74.12 & 87.61 & \multirow{4}{*}{0.105} \\
\hline & & $1^{\text {st }} \mathrm{FU} *$ & $90.47 \pm 16.97$ & 82.29 & 98.65 & \\
\hline & & $2^{\text {nd }} \mathrm{FU}$ & $91.17 \pm 14.63$ & 83.89 & 98.44 & \\
\hline & & $3^{\text {rd }} \mathrm{FU}$ & $87.79 \pm 9.58$ & 82.25 & 93.32 & \\
\hline & \multirow{4}{*}{ FEV1 } & Baseline & $68.59 \pm 21.84$ & 58.9 & 78.28 & \multirow{4}{*}{0.242} \\
\hline & & $1^{\text {st }} \mathrm{FU}$ & $78.37 \pm 21.90$ & 67.81 & 88.93 & \\
\hline & & $2^{\text {nd }} \mathrm{FU}$ & $79.44 \pm 20.85$ & 69.07 & 89.82 & \\
\hline & & $3^{\text {rd }} \mathrm{FU}$ & $81.43 \pm 19.84$ & 69.97 & 92.89 & \\
\hline & \multirow{4}{*}{ FEV1/FVC } & Baseline & $85.95 \pm 21.88$ & 76.25 & 95.66 & \multirow{4}{*}{0.895} \\
\hline & & $1^{\mathrm{st}} \mathrm{FU}$ & $90.16 \pm 18.09$ & 81.44 & 98.88 & \\
\hline & & $2^{\text {nd }} \mathrm{FU}$ & $89.44 \pm 20.53$ & 79.23 & 99.65 & \\
\hline & & $3^{\text {rd }} \mathrm{FU}$ & $86.36 \pm 21.74$ & 73.8 & 98.91 & \\
\hline & \multirow{4}{*}{ PEFR } & Baseline & $55.64 \pm 27.17$ & 43.59 & 67.69 & \multirow{4}{*}{0.492} \\
\hline & & $1^{\mathrm{st}} \mathrm{FU}$ & $62.32 \pm 28.24$ & 48.7 & 75.93 & \\
\hline & & $2^{\text {nd }} \mathrm{FU}$ & $69.72 \pm 32.41$ & 53.6 & 85.84 & \\
\hline & & $3^{\text {rd }} \mathrm{FU}$ & $65.36 \pm 29.62$ & 48.26 & 82.46 & \\
\hline & \multirow{4}{*}{ FEF2575 } & Baseline & $48.41 \pm 29.77$ & 35.21 & 61.61 & \multirow{4}{*}{0.789} \\
\hline & & $1^{\text {st }} \mathrm{FU}$ & $53.05 \pm 23.48$ & 41.73 & 64.37 & \\
\hline & & $2^{\text {nd }} \mathrm{FU}$ & $56.61 \pm 28.44$ & 42.47 & 70.75 & \\
\hline & & $3^{\text {rd }} \mathrm{FU}$ & $55.5 \pm 26.85$ & 40 & 71 & \\
\hline
\end{tabular}

$\mathrm{FU}^{*}=$ Follow up 
Table 4: Spirometry mean values progression with time (Foracort group).

\begin{tabular}{|c|c|c|c|c|c|c|}
\hline Group & & & Mean \pm SD & \multicolumn{2}{|c|}{ 95\% Confidence interval for mean } & Sign. \\
\hline \multirow{20}{*}{ Foracort } & \multirow{4}{*}{$\mathrm{FVC}$} & BASELINE & $81.68 \pm 16.64$ & 75.57 & 87.78 & \multirow{4}{*}{0.304} \\
\hline & & $1^{\mathrm{st}} \mathrm{FU}^{*}$ & $84.81 \pm 15.30$ & 78.63 & 90.99 & \\
\hline & & $2^{\text {nd }} \mathrm{FU}$ & $83.83 \pm 18.17$ & 74.79 & 92.87 & \\
\hline & & $3^{\text {rd }} \mathrm{FU}$ & $74 \pm 17.97$ & 62.58 & 85.42 & \\
\hline & \multirow{4}{*}{ FEV1 } & Baseline & $68.1 \pm 22.26$ & 59.93 & 76.26 & \multirow[t]{4}{*}{0.394} \\
\hline & & $1^{\mathrm{st}} \mathrm{FU}$ & $76.04 \pm 17.99$ & 68.77 & 83.31 & \\
\hline & & $2^{\text {nd }} \mathrm{FU}$ & $74.78 \pm 18.82$ & 65.41 & 84.14 & \\
\hline & & $3^{\text {rd }} \mathrm{FU}$ & $67.25 \pm 24.67$ & 51.57 & 82.93 & \\
\hline & \multirow{4}{*}{ FEV1/FVC } & Baseline & $84.9 \pm 18.03$ & 78.29 & 91.52 & \multirow[t]{4}{*}{0.337} \\
\hline & & $1^{\text {st }} \mathrm{FU}$ & $91.81 \pm 19.73$ & 83.84 & 99.78 & \\
\hline & & $2^{\text {nd }} \mathrm{FU}$ & $92.89 \pm 14.84$ & 85.51 & 100.27 & \\
\hline & & $3^{\text {rd }} \mathrm{FU}$ & $92.5 \pm 17.90$ & 81.13 & 103.87 & \\
\hline & \multirow{4}{*}{ PEFR } & Baseline & $50.55 \pm 22.93$ & 42.14 & 58.96 & \multirow[t]{4}{*}{0.165} \\
\hline & & $1^{\text {st }} \mathrm{FU}$ & $60.96 \pm 21.17$ & 52.41 & 69.51 & \\
\hline & & $2^{\text {nd }} F U$ & $63.28 \pm 25.58$ & 50.56 & 76 & \\
\hline & & $3^{\text {rd }} \mathrm{FU}$ & $51.33 \pm 22.83$ & 36.82 & 65.84 & \\
\hline & \multirow{4}{*}{ FEF2575 } & Baseline & $42.74 \pm 24.99$ & 33.57 & 51.91 & \multirow[t]{4}{*}{0.576} \\
\hline & & $1^{\mathrm{st}} \mathrm{FU}$ & $50.35 \pm 23.54$ & 40.84 & 59.86 & \\
\hline & & $2^{\text {nd }} \mathrm{FU}$ & $51.5 \pm 22.99$ & 40.06 & 62.94 & \\
\hline & & $3^{\text {rd }} \mathrm{FU}$ & $48.5 \pm 28.19$ & 30.59 & 66.41 & \\
\hline
\end{tabular}

$\mathrm{FU}^{*}=$ Follow up

The budecort group shows better results than foracort group in FEV1, PEFR and FEF2575 parameters as shown in progression charts. The quantum of improvement slightly increased with time in most of the cases. Such mild improvements seen in each spirometry parameter over a period of nine months from the baseline value were statistically assessed using ANOVA. The baseline mean value of each spirometry parameter was compared with mean values of same parameter obtained at three, six and nine months of study for improvement with treatment over nine months. Neither group showed statistically significant improvement in any spirometry parameter with time progression as shown in the table. No patient in either group reported any adverse effect during entire study period.

\section{DISCUSSION}

Asthma is a controllable disease in current times. The historical view of asthma being a disease of high-income countries no longer holds since most of the people affected are in low- and middle-income countries, and its prevalence is estimated to be increasing fastest in those countries. Today, $10-12 \%$ of adults and $15 \%$ of children are affected by the disease. ${ }^{1}$ The disease severity in asthma can be classified as mild, moderate and severe based on the frequency of symptoms or the severity of airflow obstruction. ${ }^{11}$
Current study compared high dose inhaled steroid option against the combination of $\beta 2$ agonists and low dose steroids in moderate persistent asthma patients. It was a randomized, prospective, comparative study. Rotacaps were used in current study as they are cost friendly and easily available everywhere. Matching rotahalers were used for drug delivery.

As the means of all spirometry parameters were compared, PEFR improved more in budecort group (by approximately 30 predicted points) but statistically it was not significant ( $p$ value 0.233 ). Time based progression of these spirometry parameters during 9 months also showed slightly better values for budecort group. (FVC by 10 predicted points, FEV1 by 15 predicted points, PEFR by 10 predicted points and FEF2575 by 5 predicted points). To know the statistical significance, percentage change from baseline was calculated for each spirometry follow up for all parameters and means were compared against respective results of other group. However, the statistical results did not show significant difference for any parameter at the end of nine months which means that either intervention showed comparable efficacy. This is an important finding because the currently used regime in moderate persistent asthma is combination therapy of LABA and low dose inhaled corticosteroids. So high dose inhaled steroid therapy used as $400 \mu \mathrm{g}$ rotacaps with matching revolizer twice a day $(800 \mu \mathrm{g}$ daily) may be good alternative to use of combination therapy particularly in patients where LABA cannot be used. 
Sample size was one of the limitations of the study. More studies on safety of high dose steroid therapy are needed to establish use of such therapy in needed patients. Despite above limitations, notable findings have been obtained from the study which can go a long way in providing additional option to the physician in the management of patients having moderate persistent asthma.

\section{CONCLUSION}

It is concluded that the two treatment groups in the study, high dose inhaled corticosteroids group (budecort) and combination of LABA and low dose inhaled corticosteroids group (foracort) were comparable. High dose steroid therapy which is as efficacious as use of combination therapy as shown by spirometry, may be an important option in patients in whom LABA are contraindicated. It can also be good alternative option for patients who experience adverse effects like tachycardia, tremors, arrhythmia while using LABA in form of combination therapy. This may be taken as an important strategy in treating cases of moderate persistent asthma which are usually managed by combination therapy.

\section{ACKNOWLEDGEMENTS}

Authors are very grateful to our college colleagues for unreserved guidance and constructive suggestions and comments from the stage of proposal development to this end. Our deepest gratitude also goes to staff workers who helped and allowed us in collecting and gathering data from the hospital.

Funding: Although it was neither insisted on patients nor sponsored, effort was made to use a single brand and single formulation to avoid problems of difference in bioequivalence, bioavailability and difference in dose delivery due to use of different delivery machines. Budecort brand was selected for first group and foracort for second group purely on the basis of easy local availability and affordable cost to patient. No benefits of any other kind were involved.

Conflict of interest: None declared

Ethical approval: The study was approved by the Institutional Ethics Committee

\section{REFERENCES}

1. Guy M, Neil P, David S, Innes A. Global burden of disease due to asthma. The Global Asthma Report 2014. Available at. http://www.globalasthma report. org/ burden/burden.php. Accessed 5 January 2016.

2. Shah JR, Amdekar YK, Mathur RS. Nationwide variation in prevalence of bronchial asthma (part of the international study of asthma and allergies in childhood-ISAAC). Indian J Med Sci. 2000;54:213-20.

3. Asthma Risk Factors. lung health and diseases. Available at. http://www.lung.org/lung-health-anddiseases/lung-disease-lookup/asthma/ asthmasymptoms-causes-risk-factors/asthma-riskfactors.html. Accessed 5 January 2016.

4. WHO. Asthma: definition. Available at. http://www.who.int/respiratory/ asthma/definition/en. Accessed 20 March 2014.

5. Dahl R. Systemic side effects of inhaled corticosteroids in patients with asthma. Respiratory medicine. 2006;100:1307-17.

6. Rossi G, Cerasoli F, Cazzola M. Safety of inhaled corticosteroids: room for improvement. Pulmonary pharmacology and therapeutics. 2007;20:23-35.

7. Rang HP, Rang HP, Dale MM, Ritter JM, Flower R, Henderson G. Editors. Pulmonary disease and its treatment. In: Rang and Dale's Pharmacology. $7^{\text {th }}$ ed. Elsevier; 2010:336-46.

8. Wijesinghe M, Perrin K, Harwood M, Weatherall M, Beasley R. The risk of asthma mortality with inhaled long acting beta-agonists. Postgrad Med Journal. 2008;84:467-72.

9. Foster C. Asthma treatment. In: Cooper D, Neville Mistry N, Peddi PF, Sharma S. Editors. Washington manual of medical therapeutics. $32^{\text {nd }}$ ed. Lippincott Williams and Wilkins; 2010:306.

10. Rodrigo GJ, Castro-Rodríguez JA. Safety of longacting $\beta$ agonists for the treatment of asthma: clearing the air. Thorax. 2012;67(4):342-9.

11. Weir NA, Levine SJ. Achieving symptom control in patients with moderate asthma. Clin Med Insights Circ Respir Pulm Med. 2012;6:1-11.

Cite this article as: Sood V, Sharma P, Bansal R, Kansal D. Comparison of efficacy of high dose inhaled corticosteroids with a combination of low dose inhaled corticosteroids and long acting $\beta 2$ agonists in patients of moderate persistent asthma: a randomised prospective comparative study. Int $\mathbf{J}$ Basic Clin Pharmacol 2016;5:929-34. 